\title{
Drought induces opposite changes in the concentration of non-structural carbohydrates of two evergreen Nothofagus species of differential drought resistance
}

\author{
Frida I. Piper
}

Received: 21 May 2010 / Accepted: 22 July 2010 / Published online: 17 February 2011

(C) INRA and Springer Science+Business Media B.V. 2011

\begin{abstract}
- Introduction One current explanation for worldwide drought-induced tree mortality states that reduced photosynthesis and continued respiration lead to carbon depletion and eventually to carbon starvation.

- Methods To determine if variations in gas exchange are consistent with variations in carbon storage, and if such consistency may depend on the drought resistance of a species, I examined the non-structural carbohydrates (NSC) concentration and gas exchange in seedlings of two Nothofagus species of differential drought resistance under severe drought-just before death-and under wellwatered conditions.

- Results and discussion Drought provoked decreased photosynthesis and had no effect on leaf respiration in both species, whereas NSC concentrations varied oppositely: it decreased in the relatively more drought-susceptible species (Nothofagus nitida) whilst it increased in the relatively more drought-resistant species (Nothofagus dombeyi). Thus, if carbon balance would have been inferred from gas exchange alone, I would have wrongly concluded that carbon depletion occurred in both species. In stressed seedlings of $N$. nitida, photosynthesis and NSC concentrations were negatively correlated in roots $\left(r_{2}=-0.57, p=\right.$ $0.03)$ and not correlated in stems $\left(r_{2}=-0.05, p=0.58\right)$, indicating that carbon depletion due to reduced photosynthesis was not occurring at harvest time, but it took place earlier when water stress was milder.
\end{abstract}

Handling Editor: Erwin Dreyer

F. I. Piper $(\bowtie)$

Centro de Investigación en Ecosistemas de la Patagonia (CIEP),

Bilbao 449 Coyhaique, Chile

e-mail: fpiper@ciep.cl
- Conclusions Results demonstrate that carbon depletion cannot be predicted from measurements of gas exchange. Drought-induced mobilization of carbon storage appeared influenced by the drought resistance of the species and by drought intensity.

Keywords Carbon starvation hypothesis - Carbon storage Climate change $\cdot$ Drought $\cdot$ Photosynthesis

\section{Introduction}

Worldwide massive tree mortality is one of the most evident and concerning effects of drought associated with climate change (Adams et al. 2009; Allen et al. 2010; Bréda et al. 2006; Liang et al. 2003; van Mantgem et al. 2009). The mechanisms involved in drought-induced tree death, however, remain unclear (McDowell et al. 2008; Sala et al. 2010). One appealing explanation that was suggested earlier (Parker and Patton 1975) and that emerged again later (Adams et al. 2009; Bréda et al. 2006; McDowell et al. 2008) is that drought produces a decrease in the reserves of carbohydrates (i.e., carbon depletion, Sala et al. 2010) of plants and eventually mortality. The reasoning behind this explanation is basically as follows: (1) drought produces stomatal limitations on photosynthesis, (2) the level of photoassimilates (carbohydrates) decreases, (3) metabolic demand for carbohydrates is no longer met by photosynthesis, (4) carbohydrates are mobilized from storage to satisfy a continued metabolic demand, and (5) concentrations of carbohydrates in storage sites decrease leading to carbon depletion (McDowell et al. 2008). Accordingly, it is proposed that if drought persists the whole-plant carbon demand for growth and maintenance becomes progressively greater than the whole-plant carbon availability (i.e., current 
photosynthesis plus storage), resulting in an increasing and ultimately lethal carbon imbalance. Isohydric species are believed to be more prone to suffer carbon depletion under drought since they avoid low leaf water potentials by closing their stomata earlier than anisohydric species (McDowell et al. 2008). The hypothesis of carbon depletion as the physiological consequence of drought-limited tree carbon gain that may trigger tree mortality has not been demonstrated yet, though an increasing number of studies based on gas exchange measurements, hydraulic relationships, and/or growth rate have been invoking this explanation (Adams et al. 2009; Allen et al. 2010; Liang et al. 2003; McDowell et al. 2008; McDowell et al. 2009). It may be inappropriate, however, to conclude that variations in carbon storage are the result of only some of the physiological mechanisms that control the plant carbon balance (e.g., photosynthesis, leaf water potential), given that carbon balance is controlled by a complex net of multiple drought-responsive physiological mechanisms (Chapin et al. 1990; Sala et al. 2010). An enhanced comprehension of the effects of drought on plant carbon storage seems urgent, as the geographical extent and the intensity of drought are predicted to increase around the world (IPCC 2007). Direct measurements of carbon storage on plants that have been affected by drought integrate all the physiological mechanisms involved in plant carbon storage, and thus, appear to be a more adequate approach to judge if carbon depletion does occur.

Since the early study of Parker and Patton (1975), research on drought effects on carbon balance in plants has been focused mainly on the mechanisms constraining carbon gain, while the effects of drought on the carbon demands (i.e., sink activity) have received less attention. The concept of drought-induced carbon depletion emerged following this tendency, and it was supported by some experimental (Guehl et al. 1993) and observational studies (Bréda et al. 2006). Sink activity, however, is also limited by drought (Chapin et al. 1990) and hence, carbon depletion is one of the three possible results of the interaction between whole-plant carbon gain and wholeplant carbon demands, where the other two are an increase in carbon reserves (i.e., carbon accumulation) and no carbon storage change (Sala et al. 2010). Some plants, especially the best adapted to drought, can downregulate their carbon demands under drought conditions through responses like decreased respiration (Bryla et al. 2001; Liu et al. 2004), leaf shedding (Chaves et al. 2009), and/or limited growth (Chapin et al. 1990; Sala and Hoch 2009). The downregulation of carbon demands implies that plants may experience an increase in their carbon reserves in some portion of the drought period. Another effect of drought on plant physiology that could prevent plants from experiencing carbon depletion is an accentuated impediment on carbon mobilization and translocation (Sala et al. 2010).
Still under well-watered conditions, carbon mobilization appears to be limited beyond a certain threshold because some levels of carbon are necessary for essential metabolic function in the storage sites (Millard et al. 2007). This probably explains why plants fail in the use of carbon reserves as a substitute of current photosynthesis following herbivory (Carpenter et al. 2008) or deep shade (Lusk and Piper 2007; Piper et al. 2009). The access of trees to their own carbon reserves has been found to be even more limited under drought conditions (Carpenter et al. 2008; Ruehr et al. 2009). This means that even if carbon gain has been strongly reduced by drought and does not match carbon demands, carbon depletion is not necessarily going to occur. In fact, an increase in carbon reserves has been found in many species experiencing seasonal droughts, including isohydric species like pines (Latt et al. 2001; Ludovici et al. 2002; Tissue and Wright 1995; Würth et al. 2005) or under topographically induced drought (Sala and Hoch 2009). As these studies were carried out on tree species that have passed the filters of natural selection for such drought situations, it is suggested that droughtinduced accumulation of carbon reserves in response to drought might be more prone to happen in those genotypes better adapted to drought. Consistently, Regier et al. (2009) found that the concentration of non-structural carbohydrates (NSC) increased in a drought-tolerant clone of Populus nigra submitted to an experimental drought, while the opposite was observed in a drought-intolerant clone of the same species. Thus, the drought resistance of a genotype may be an important factor in determining whether carbon depletion does occur.

I experimentally assessed the effect of a gradual drought on the carbon storage of two isohydric evergreen species of Nothofagus of differential drought resistance Nothofagus dombeyi (Mirb.) Oerst and Nothofagus nitida (Phil.) Krasser by comparing the concentrations of NSC in seedlings affected and not affected by drought. I also examined responses of gas exchange and leaf shedding to drought in order to accomplish a more complete interpretation of the mechanisms involved in the variation of carbon storage. Drought was developed slowly and gradually to favor conditions inducing carbon depletion and to avoid rapid seedling mortality (McDowell et al. 2008). Three questions were addressed in this study: (1) Does drought provoke a decrease of NSC concentrations in the isohydric species Nothofagus nitida and Nothofagus dombeyi? (2) Does the differential drought resistance of the species matter in the responses of NSC concentration to drought? and (3) Can carbon depletion be predicted from gas exchange data? I predict that the less drought-resistant species may be more prone to experience carbon depletion and that gas exchange measurements may be insufficient to predict carbon depletion. 


\section{Materials and methods}

\subsection{Plant material and growth conditions}

Seedlings of 2-3-year-old and 20-30 cm tall of $N$. dombeyi (Mirb.) Oerst. and N. nitida (Phil.) Krasser were collected in June 2004 from second-growth forests on the seaward (west-facing) slopes of the Coastal Range of Valdivia, Chile $\left(39^{\circ} 58^{\prime} \mathrm{S}, 73^{\circ} 33^{\prime} \mathrm{W}\right)$. The two species hardly ever grow together (Weinberger 1973), and they were selected to represent different drought resistances in related evergreen species: $N$. dombeyi is more drought-resistant than $N$. nitida (Piper et al. 2007). Common distribution of $N$. dombeyi here ranges from sea level to $150 \mathrm{~m}$ a.s.l and $N$. nitida ranges from $340 \mathrm{~m}$ a.s.l. to upper elevations. In particular, $N$. dombeyi was collected at $80 \mathrm{~m}$ elevation $\left(39^{\circ} 58^{\prime} 02^{\prime \prime} \mathrm{S}, 73^{\circ} 33^{\prime} 39^{\prime \prime} \mathrm{W}\right)$ and $N$. nitida at $350 \mathrm{~m}\left(39^{\circ} 59^{\prime} 40^{\prime \prime} \mathrm{S}, 73^{\circ} 34^{\prime} 12^{\prime \prime} \mathrm{W}\right)$. This area experiences a temperate maritime climate with an average annual temperature of $10^{\circ} \mathrm{C}$ and a mean annual precipitation of 3,000 $\mathrm{mm}$ at sea level (Almeyda and Saez 1958). The driest period of the year is summer (January-March), when mean monthly precipitation is $250 \mathrm{~mm}$. Although there are no permanent meteorological stations at the altitudes of the stands of seedlings collection, summer precipitation on the western side of the Coastal Range increases with altitude by ca. $50 \mathrm{~mm} / 100 \mathrm{~m}$ (Almeyda and Saez 1958). Soils of $N$. dombeyi stands are sandier and have lower water retention than soil of N. nitida stand (Piper et al. 2007).

Seedlings were carefully extracted from the soil, transplanted to $3 \mathrm{~L}$ volume $\times 20 \mathrm{~cm}$ height plastic pots and immediately transported to the greenhouse at the Universidad Austral de Chile (Valdivia, Chile). Pot substrate consisted of a mixture 1:1 of soils from each of the two stands of seedling collection. I did not collect seeds for seedling production neither germinant seedlings because of low seed availability and seedling frequency: seed production of Nothofagus species responds to masting events which happen each 5-10 years; moreover, the percentage of viable seeds can be seriously reduced during these events (Veblen et al. 1996). Although seedlings had probably some differences in their origin, like the soil texture (Piper et al. 2007), I discard this factor as a noise because acclimation of plant physiology happens rapidly and the period of acclimation was long enough (see below). Also, I avoided interspecific comparisons of the parameter measured and rather, emphasized my efforts in the interspecific comparison of the responses (drought versus control).

In the greenhouse, pots were randomly arranged and regularly watered and rotated for five months prior to the beginning of the experiment, allowing acclimation to the new soil and light environment. Average daily photosynthetic photon flux density inside the greenhouse was 400 $600 \mu \mathrm{mol} \mathrm{m}{ }^{-2} \mathrm{~s}^{-1}$ and mean air temperature was $15^{\circ} \mathrm{C}$. All seedlings produced new leaves and elongated their shoots after transplanting.

\subsection{Drought experiment}

The experiment started on November 18 of 2004, when watering was discontinued for 28 and 26 individuals of $N$. dombeyi and $N$. nitida, respectively (hereafter, stressed seedlings), whereas eight seedlings of each species continued to be watered as controls. As the environmental conditions in the greenhouse (see above) promoted a low evaporative demand, soil dried gradually at a rate of about $0.4 \%$ per day. This is important to note as the carbon depletion is not expected to occur when drought develops abruptly (McDowell et al. 2008). On January 7 of 2005, eight living stressed seedlings of each species and treatments were harvested for NSC determination and leaf nitrogen analyses. At the time of harvest, mortality had begun to happen in both species and all living stressed seedlings were appreciably affected by drought (wilt aspect, dessication of leaves). I quantified the stress level experienced by seedlings at harvest time by measuring the maximum quantum yield of PSII $(\mathrm{Fv} / \mathrm{Fm})$ in controls and living stressed seedlings following procedures described in Piper et al. (2007). In stressed plants of $N$. nitida, Fv/Fm was 0.62 (standard error $=0.05$ ), while in stressed $N$. dombeyi, it was 0.61 (standard error $=0.06$ ). Similar values of $\mathrm{Fv} / \mathrm{Fm}$ have been reported to cause a seedling mortality higher than $50 \%$ in studies assessing drought effects on tree species (e.g., Percival and Sheriffs 2002; García-Plazaola and Becerril 2000). Control plants of both species had an $\mathrm{Fv} / \mathrm{Fm}$ of 0.84 . The remaining non-harvested living stressed plants were maintained under drought until death. The experiment ended when all the remainder stressed plants had died by January 20 of 2005. Soil moisture was measured weekly as volumetric water content (VWC $=$ water vol/soil vol $\times 100$ ) using a time domain reflectometry (TDR) soil moisture meter (Trimelog, Ettlingen, Germany). The value for each pot was determined from the average of three measurements made at $18 \mathrm{~cm}$ depth (the length of the TDR' probes) at equidistant points. During the experimental period, VWC averaged $20.18 \%$ and $21.45 \%$ in control seedlings of $N$. dombeyi and $N$. nitida, respectively, whereas it progressively decreased in stressed plants. Soil VWC of stressed seedlings that were harvested was $2.2 \%$ $( \pm 0.3)$ for $N$. dombeyi and $4.6 \%( \pm 0.6)$ for $N$. nitida, while VWC of the remainder stressed plants at time of death was $1.1( \pm 0.1)$ for $N$. dombeyi and $3.9( \pm 0.3)$ for $N$. nitida. As VWC of harvested stressed plants was about $95 \%$ of the difference in VWC between control and dead plants, the drought level at harvest time will be referred as drought ${ }_{95} \%$. Gas exchange and soil VWC were measured weekly in five to ten randomly selected stressed seedlings of each species 
to evaluate whether continued respiratory demand and decreased carbon gain from photosynthesis are underlying factors in drought-induced mortality. The number of replicates decreased to five in the last weeks of measurements as several plants had died and others had already been harvested for NSC analyses. Before harvest, gas exchange was also measured on these seedlings.

\subsection{Gas exchange measurements}

Net rate of carbon assimilation, stomatal conductance, and respiration rate of sunlit and fully expanded leaves were measured with a portable infrared gas analyzer, differential open system (Ultra Compact Photosynthesis System, LCi, ADC Bioscientific Ltd., UK). System flow rate was controlled at $300 \mathrm{ml} \mathrm{min}^{-1}$. The LCi was equipped with a broadleaf cuvette that measures gas exchange of a $6.25 \mathrm{~cm}^{2}$ area of a leaf. The cuvette $\mathrm{CO}_{2}$ concentration was $350 \mathrm{ppm}$. All measurements were made at greenhouse ambient light conditions on sunny days on leaves produced during the acclimation period. Photosynthesis and stomatal conductance were recorded between 0900 and 1100 hours. Instead of imposing darkness on seedlings during the day (in order to avoid potential influence of circadian rhythm), respiration was recorded at night, between 22:00 and 24:00 hours. At the time of measurements, air temperature was $15^{\circ} \mathrm{C}$ and the relative humidity about $30 \%$.

\subsection{Harvesting}

Seedlings were harvested between 16:00 and 18:00 hours for NSC and N analyses. Soil was carefully removed from the roots, and plants were dissected into leaves, stem, and roots. Tissues were packed in labeled paper bags, dried to a constant weight at $70^{\circ} \mathrm{C}$, and dry weight was recorded. The dried samples were then ground with a coffee mill to a fine powder status. Before harvest, detached leaves were collected from the surface of the pots, carefully cleaned, and processed in the same manner as the other tissues, in order to estimate leaf shedding. Leaf shedding was calculated as the percentage of dry weight of shed leaves relative to dry weight of all leaves (attached and detached).

\subsection{NSC and N analyses}

Roots and stems of each seedling were analyzed for NSC. These tissues constitute the main storage sites in most woody plants (Chapin et al. 1990). Total soluble sugars (TSS) were extracted from tissues in $80 \% v / v$ ethanol at $80^{\circ} \mathrm{C}$ for $1 \mathrm{~h}$ (Hansen and Moller 1975). The supernatant was collected by centrifugation $\left(1,360 \times \mathrm{g}\right.$ at $4^{\circ} \mathrm{C}$ for $5 \mathrm{~min}$.) and TSS concentration was determined spectrophotometrically by the Resorcinol procedure (Roe 1934) at a wavelength of $520 \mathrm{~nm}$, using sucrose as standard. Starch was extracted from the ethanol insoluble fraction with agitation with $35 \% v / v$ perchloric acid for $1 \mathrm{~h}$ (Sutton et al. 1981). Analysis for starch was the same as that used for sugars, but instead using glucose as standard. TSS was expressed in mg per gram of dry weight, whereas starch was expressed as mg of glucose per gram of dry weight. Contents of non-structural carbohydrates (NSC) were obtained for roots and stems of each seedling by adding starch and TSS. The ratio between TSS concentration and starch concentration was calculated for each plant ([TSS/ Starch] ratio) to evaluate drought-induced changes in mobilization-accumulation and in osmotic adjustments. Total leaf nitrogen $(\mathrm{N})$ was analyzed on attached leaves by the Kjeldahl method and expressed as a percentage of leaf dry weight (Laboratorio de Análisis de Suelos y Plantas of Facultad de Agronomía, Universidad de Concepción, Chillán, Chile).

\subsection{Statistical analyses}

Two-way ANOVA tests were used to compare responses between seedlings at drought $95 \%$ and control seedlings in both species. This test was performed for gas exchange, NSC concentrations, and leaf $\mathrm{N}$ concentration, with species and treatment as fixed effects, using the software JMP 8.0.2.2. Leaf shedding, which occurred only in seedlings at drought $_{95 \%}$, was compared between species by a Student's $t$ test. For each species, the effect of drought on TSS concentrations, starch concentration, and [TSS/Starch] ratio was also evaluated by a Student's $t$ test. These analyses were performed using Sigma Stat 3.10 software. Simple correlation analyses were run between photosynthesis and NSC concentrations in seedlings at drought ${ }_{95 \%}$ to determine if changes in carbon reserves were associated with rates of photosynthesis.

The statistical package (S)MATR (Version 1, Falster DS, Warton DI \& Wright IJ http://www.bio.mq.edu.au/ecology/ SMATR) was used to examine relationships of gas exchange parameters and soil water content within each species. A series of gas exchange and soil water content measurements recorded along the gradient of drought were analyzed by a type II linear regression fitted for each species. (S)MATR computes standardized major axis (SMA) which is similar to linear regression, although residuals from the regression line are estimated in both the $x$ - and $y$-axes. The SMA analysis is appropriate when the objective of the analysis is to estimate the relationship between two variables, particularly when the slope of the relationship is of primary interest (Falster et al. 2003).

\section{Results}

Drought provoked opposite changes in the NSC concentrations of the study species: a significant decrease in NSC 
Table 1 Summary of two-way ANOVA testing for effects of species and treatments (control versus drought $_{95 \%}$ ) on gas exchange parameters, leaf nitrogen concentration, and concentrations of non-structural carbohydrates (NSC) in roots and stems of two evergreen species of Nothofagus from southern Chile. Control seedlings were well-watered during the experimental period. Drought $_{95 \%}$ refers to seedlings whose soil moisture was $95 \%$ lower than control plants, considering as $100 \%$ the difference of volumetric water content (VWC) between controls and seedlings that died due to drought

\begin{tabular}{lllcc}
\hline Response Variable & Effect & $d f$ & $F$ ratio & $p$ value \\
\hline Leaf respiration $\left(\mu \mathrm{mol} \mathrm{m}^{-2} \mathrm{~s}^{-1}\right)$ & Species & $1(31)$ & 5.36 & 0.48 \\
& Treatment & $1(31)$ & 1.26 & 0.25 \\
& Treatment $\times$ species & $1(31)$ & 0.35 & 0.89 \\
Photosynthetic rate $\left(\mu \mathrm{mol} \mathrm{m}^{-2} \mathrm{~s}^{-1}\right)$ & Species & $1(31)$ & 5.26 & 0.03 \\
& Treatment & $1(31)$ & 110.2 & $<0.001$ \\
& Treatment $\times$ species & $1(31)$ & 34.3 & $<0.001$ \\
Stomatal conductance $\left(\mu \mathrm{mol} \mathrm{m}^{-2} \mathrm{~s}^{-1}\right)$ & Species & $1(31)$ & 0.904 & 0.35 \\
& Treatment & $1(31)$ & 113.5 & $<0.001$ \\
& Treatment $\times$ species & $1(31)$ & 2.33 & 0.138 \\
Leaf N concentration $(\%)$ & Species & $1(31)$ & 8.04 & 0.008 \\
& Treatment & $1(31)$ & 0.92 & 0.346 \\
& Treatment $\times$ species & $1(31)$ & 0.88 & 0.356 \\
& Species & 1 & 10.972 & 0.003 \\
& Treatment & 1 & 0.017 & 0.896 \\
& Treatment $\times$ species & 1 & 6.278 & 0.003 \\
& Species & 1 & 2.832 & 0.104 \\
& Treatment & 1 & 5.293 & 0.029 \\
& Treatment $\times$ species & 1 & 4.337 & 0.047 \\
\hline $\mathrm{NSC}]_{\text {root }}$ & & &
\end{tabular}

concentration (carbon depletion) was observed only in the relatively more drought-susceptible species ( $N$. nitida), while the relatively more drought-resistant species $(N$. dombeyi) experienced an increase in NSC concentration (Tables 1, 2). In N. dombeyi, the NSC concentration of the stems increased $15 \%$ in response to drought, while the NSC concentration of roots did not vary significantly (Tables 1 and 2). In $N$. nitida, on the contrary, the concentrations of NSC decreased in response to drought; when compared to control, seedlings at drought $_{95 \%}$ had $38 \%$ less NSC concentration in roots and $12 \%$ lower in stems (Tables 1 and 2). In spite of the severe water stress experienced by $N$. nitida at drought $_{95 \%}$, levels of carbon reserves remained relatively high, where the lowest NSC concentration observed was $6.8 \%$ of dry weight.

The main component of NSC was starch, accounting by more than $63 \%$ of NSC in all seedlings (Table 2). Then, though TSS levels were also affected by drought, changes in NSC were mainly due to changes in starch concentration (Table 2). In N. dombeyi, controls and seedlings at drought $_{95 \%}$ had similar levels of TSS (stems: $t=-0.57, p=$ 0.576 ; roots: $t=0.80 p=0.435$ ) while starch concentration in

Table 2 Concentrations of total soluble sugars (TSS), starch, and non-structural carbohydrates (NSC) in large seedlings of Nothofagus spp. submitted to an experimentally induced drought for 2 months

\begin{tabular}{|c|c|c|c|c|}
\hline & \multicolumn{2}{|c|}{ Nothofagus dombeyi } & \multicolumn{2}{|l|}{ Nothofagus nitida } \\
\hline & control & Stress $_{95 \%}$ & Control & Stress $_{95 \%}$ \\
\hline$[\mathrm{TSS}]_{\text {stem }}$ & $46.2( \pm 1.4) \mathrm{a}$ & $47.7( \pm 2.2) \mathrm{a}$ & $43.9( \pm 2.3) \mathrm{a}$ & $44.0( \pm 3.0) \mathrm{a}$ \\
\hline$[\text { Starch }]_{\text {stem }}$ & $145.3( \pm 6.2) \mathrm{a}$ & $177.8( \pm 10.0) \mathrm{b}$ & $147.7( \pm 4.7) \mathrm{a}$ & $124.3( \pm 9.4) b$ \\
\hline$[\mathrm{NSC}]_{\mathrm{stem}}$ & $191.6( \pm 7.2) \mathrm{a}$ & $225.6(10.1) \mathrm{b}$ & $191.7( \pm 4.5) \mathrm{a}$ & $168.3( \pm 11.6) b$ \\
\hline$[\mathrm{TSS}]_{\mathrm{root}}$ & $32.9( \pm 1.5) \mathrm{a}$ & $31( \pm 1.8) \mathrm{a}$ & $32.9( \pm 1.7) \mathrm{a}$ & $27.1( \pm 2.1) \mathrm{b}$ \\
\hline$[\text { Starch }]_{\text {root }}$ & $127.2( \pm 18.2) \mathrm{a}$ & $125.9( \pm 17.0) \mathrm{a}$ & $132.9( \pm 13.3) \mathrm{a}$ & $75.6( \pm 7.4) b$ \\
\hline$[\mathrm{NSC}]_{\mathrm{root}}$ & $160.1( \pm 18.4) \mathrm{a}$ & $156.9( \pm 16.5)$ a & $165.8( \pm 12.2) \mathrm{a}$ & $102.7( \pm 8.3) b$ \\
\hline$([\mathrm{TSS}] /[\mathrm{Starch}])_{\text {stem }}$ & $0.32( \pm 0.01) \mathrm{a}$ & $0.27( \pm 0.02) b$ & $0.30( \pm 0.02) \mathrm{a}$ & $0.37( \pm 0.03) \mathrm{a}$ \\
\hline$([\mathrm{TSS}] /[\mathrm{Starch}])_{\text {root }}$ & $0.27( \pm 0.04) \mathrm{a}$ & $0.29( \pm 0.03) \mathrm{a}$ & $0.27( \pm 0.04) \mathrm{a}$ & $0.38( \pm 0.04) \mathrm{a}$ \\
\hline
\end{tabular}

Units of the values correspond to $\mathrm{mg} / \mathrm{g}$ dry weight (DW). Control seedlings were well-watered during the experimental period. Drought ${ }_{95 \%}$ refers to seedlings whose soil moisture was $95 \%$ lower than control plants, considering as $100 \%$ the difference of volumetric water content (VWC) between controls and seedlings that died due to drought. Values are the average of one measurement per plant $(n=8)$; standard errors are in parenthesis. Lower case letters represent intraspecific comparisons between treatments by a Student's $t$ test; different letters indicate significant differences 
stems was higher in seedlings at drought $_{95 \%}$ (stems: $t=-2.82, p=0.01$; roots: $t=0.05, p=0.961)$. In $N$. nitida, on the contrary, seedlings at drought ${ }_{95 \%}$ had lower levels of TSS (stems: $t=-0.01, p=0.99$; roots: $t=2.13, p=0.05$ ) and starch (stem: $t=2.21, p=0.043$; roots: $t=3.77, p=0.002$; Table 2). Regarding controls, seedlings of $N$. nitida at drought $_{95 \%}$ had higher $[\mathrm{TSS} / \mathrm{Starch}]$ ratio in both roots $(t=-1.97, p=0.07)$ and stems $(t=-1.65, p=0.12)$, though the differences were not significant. In the stems of $N$. dombeyi, drought promoted a significant decrease in the [TSS/Starch] ratio $(t=2.4, p=0.03)$; whereas in the roots, no variation was observed in response to drought (Table 2).

Photosynthesis and stomatal conductance were severely reduced in seedlings at drought ${ }_{95 \%}$ of both species (Table 1, Fig. 1). Responses were more drastic in N. nitida than in $N$. dombeyi (e.g., significant interaction terms between species and treatment) where photosynthesis was reduced $87 \%$ and $68 \%$, respectively. Leaf respiration rate was similar between species (Table 1) and was not affected by drought, though it

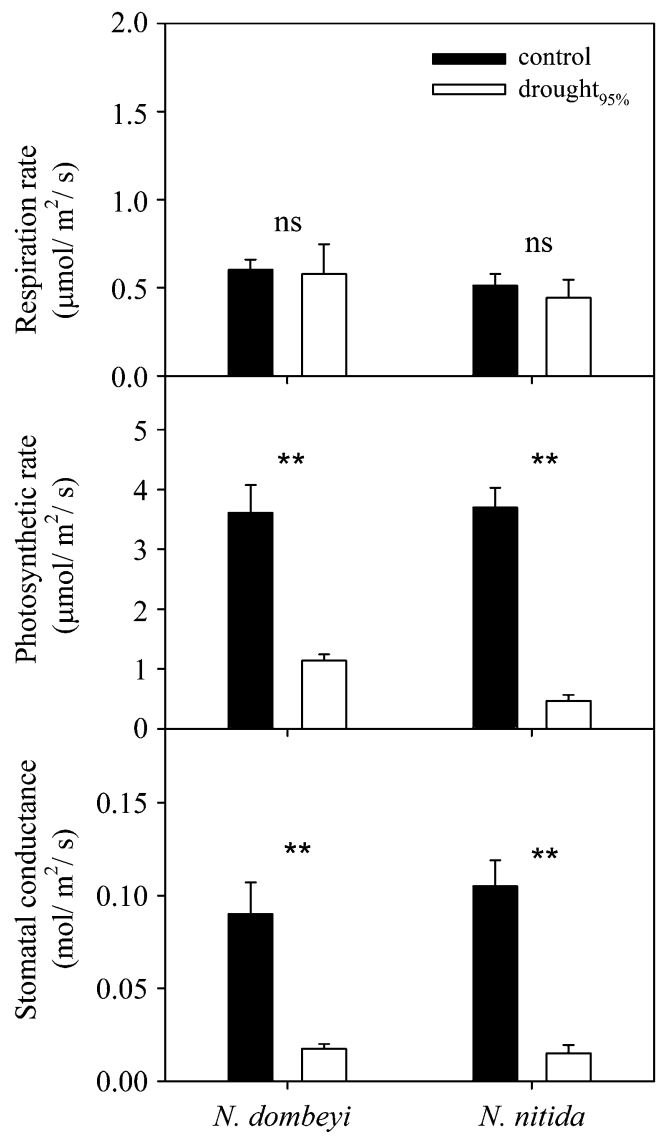

Fig. 1 Effect of an experimentally induced drought on gas exchange of large seedlings of two Nothofagus species. Control seedlings were well-watered during the experimental period. Drought ${ }_{95 \%}$ refers to seedlings whose soil moisture was $95 \%$ lower than control plants, considering as $100 \%$ the difference of soil volumetric water content (VWC) between controls and seedlings that died due to drought. Bars represent the average of one leaf measurement per seedling $(n=8)$; error bars represent average standard errors tended to decrease in seedlings of $N$. nitida at drought ${ }_{95 \%}$ (Table 1, Fig. 1).

Although drought appeared reducing both photosynthesis and NSC concentrations of $N$. nitida, these parameters were negatively correlated in roots $\left(r^{2}=-0.57, p=0.03\right)$ and not correlated in stems $\left(r^{2}=-0.05, p=0.58\right.$; Fig. 2), indicating that the decreased input of photoassimilates was not responsible for the carbon depletion. Likewise, the increase of NSC concentration in stems of $N$. dombeyi was not related to photosynthesis $\left(r^{2}=0.011, p=0.93\right)$, indicating that seedlings with the highest photosynthesis were not those that accumulated more NSC.

Gas exchange responses during the entire drought period were consistent with the ones found in the comparison between controls and seedlings at drought ${ }_{95 \%}$. Stomatal conductance decreased similarly in both species, whereas photosynthesis decreased more drastically in $N$. nitida (Fig. 3). Respiration did not change significantly in either species (Fig. 3). Leaf nitrogen content was slightly higher in $N$. dombeyi (mean $=1.02 \%$, standard error $=0.06$ ) than in $N$. nitida $($ mean $=0.91 \%$, standard error $=0.08$ ). Consistent with a lack of trend observed for respiration, leaf nitrogen concentration did not vary either in response to drought (Table 1). At time of harvesting, both species had shed leaves though no seedling shed more than $15 \%$ of the total leaf final biomass. The relative biomass of shed leaves was significantly higher $(t=-3.008, p=0.012)$ for $N$. dombeyi (mean $=13.1 \%$, standard error $=2.6)$ than for $N$. nitida $($ mean $=5.6 \%$, standard error $=1.1)$.

\section{Discussion}

This study clearly shows that although drought provoked important reductions in photosynthesis of seedlings of both Nothofagus species, carbon depletion was found only in the relatively more drought-susceptible species ( $N$. nitida). Contrary, severe drought caused an increase in the carbon reserves of the relatively more drought-resistant species $(N$. dombeyi). This result indicates that, in one of the study species, variation in gas exchange was not linked to changes in carbon storage, demonstrating the importance of direct measurements of carbon storage in order to evaluate drought effects on carbon balance. Based on hydraulic and gas exchange measurements, a potential explanation for drought-induced tree mortality is that curtailed photosynthesis and continued demand for carbohydrates lead to carbon depletion and eventually to carbon starvation and tree death (McDowell et al. 2008). The hypothesis proposed by McDowell et al. (2008) has been invoked when decreased photosynthesis and persistent leaf respiration happened concomitantly (Adams et al. 2009). In the current investigation, if carbon balance would have 

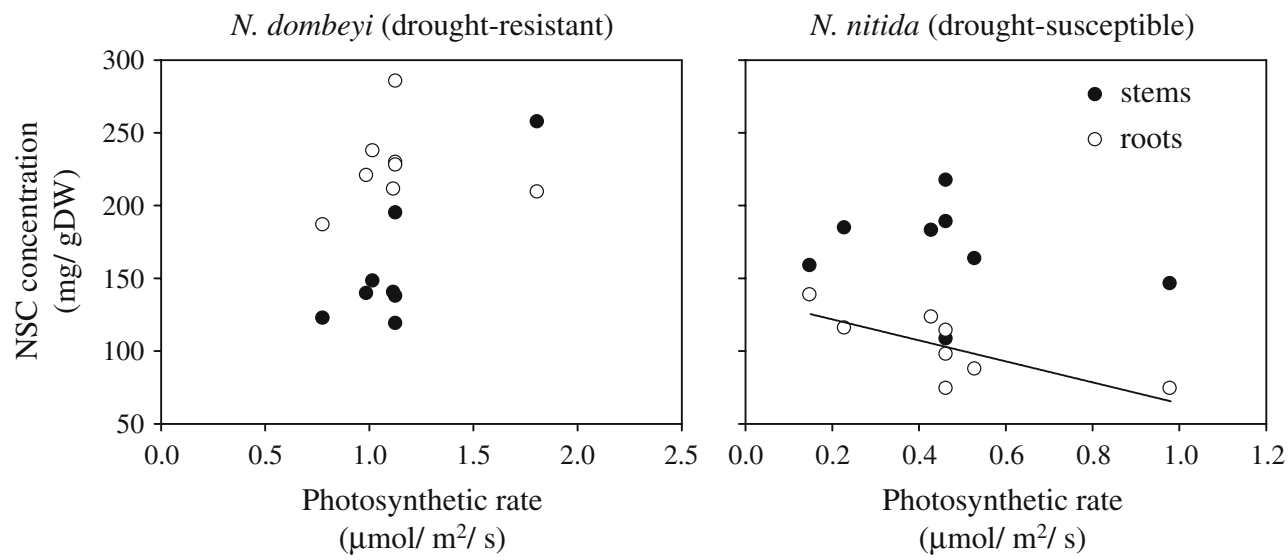

Fig. 2 Relationship between stem and root NSC concentration and photosynthetic rate in seedlings of two Nothofagus species submitted to drought conditions. Drought was equivalent to a value of soil moisture $95 \%$ lower than control seedlings, considering as $100 \%$ the difference of volumetric water content (VWC) between controls and

seedlings that died due to drought. Each circle corresponds to one seedling. Only linear regression between photosynthetic rate and NSC concentration of stems in $N$. nitida was statistically significant $(p=0.03)$

been inferred from gas exchange solely, I would have incorrectly concluded that $N$. dombeyi experienced carbon depletion because carbohydrate demand for leaf respiration continued and photosynthetic rate decreased as the drought intensity progressed. Thus, direct measurements of carbon storage appear to be critical in testing potential droughtinduced carbon depletion or carbon starvation.

Results are furthermore revealing regarding the level of water stress when gas exchange produces carbon depletion. Consistent with the reasoning of the carbon starvation hypothesis, carbon depletion in $N$. nitida occurred along with a strong decrease in photosynthesis and a continued demand for leaf respiration. However, it is noteworthy that no positive association was found between photosynthesis and NSC concentrations in seedlings of $N$. nitida at drought $_{95 \%}$, and furthermore, a negative correlation was observed for root NSC concentration and photosynthesis in these seedlings. These results indicate that the mechanistic explanation for drought-induced carbon depletion - that low stomatal conductance and photosynthesis stimulate the use of carbon reserves to meet continued carbon demands - was not supported at levels of water stress as severe as drought ${ }_{95 \%}$. Rather, it is likely that seedlings of $N$. nitida underwent drought-induced carbon depletion during the first weeks of the drought experiment when water stress was less intensive than at drought $95 \%$ and that carbon mobilization became limited with the intensification of the drought. It has been recently highlighted that severe drought probably impairs some mechanisms involved in the mobilization and use of carbon reserves, such as starch hydrolysis or phloem transport of mobile forms of carbon (Sala et al. 2010). The negative association between photosynthesis and NSC concentration experienced by $N$. nitida at drought ${ }_{95 \%}$ seems to support the proposal of Sala et al. (2010).

Opposite effects of drought on NSC concentration in closely related genotypes of differential drought resistance, similar to those that I found in this study, have been reported elsewhere (Regier et al. 2009). These results suggest that drought-induced variation in the carbon storage of isohydric species may depend on the drought-adaption of the genotype. The increase in carbon reserves found in the relatively more drought-resistant species $N$. dombeyi is consistent with results from other studies assessing carbon storage under drought conditions in genotypes adapted to drought (Latt et al. 2001; Regier et al. 2009; Sala and Hoch 2009; Würth et al. 2005). Furthermore, this finding indicates that drought constrained the processes related to the use of carbon (carbon sink demand) more than the processes associated with carbon gain (Sala et al. 2010). Consistently, the decrease in the [TSS/Starch] ratio along with the increase in the starch concentration in stems of $N$. dombeyi reveals that when this species was subjected to drought the synthesis of reserve compounds prevailed over the consumption of carbon reserves (Chapin et al. 1990). In contrast, $N$. nitida experienced a reduction in starch concentrations in response to drought, consistent with the notion that the whole carbon demand of the seedlings was relatively higher than the whole carbon gain. Although leaf shedding was not very high for either species, the differences in leaf shedding between the two species could account, in part, for the opposite effects of drought on NSC concentrations. Under drought conditions, leaves from previous seasons usually reduce their photosynthesis to levels that do not offset respiration costs, implying that there is a less positive carbon balance at whole-plant level (Chaves et al. 2009). By shedding leaves, plants reduce the proportion of tissue with negative carbon balance, thus improving the whole-plant carbon balance and increasing 


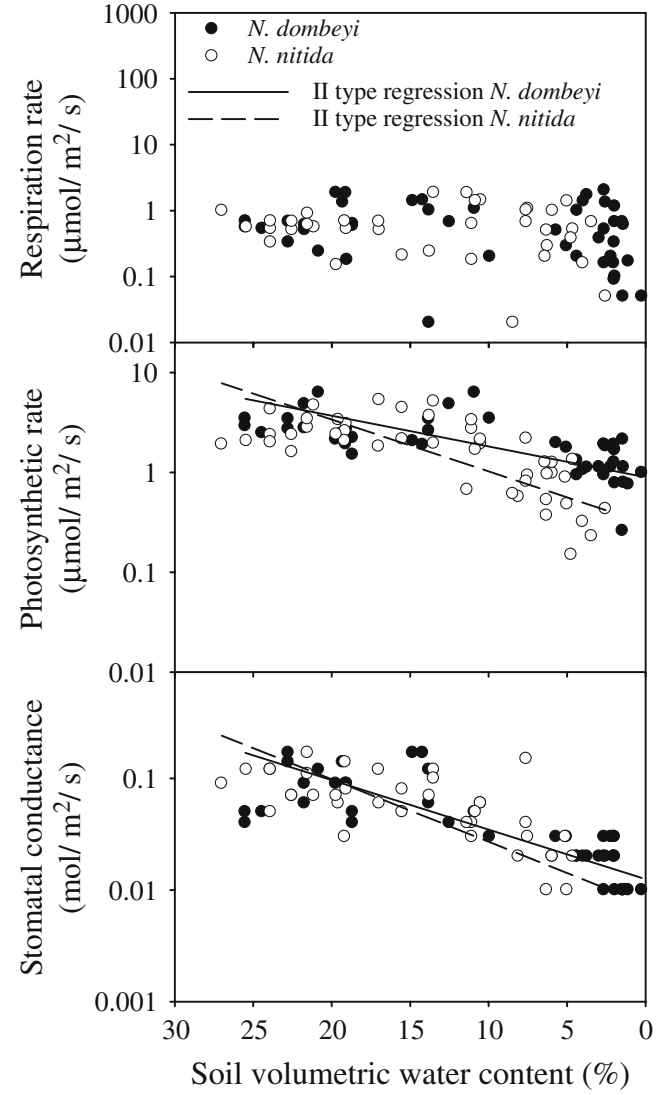

Fig. 3 Effects of an experimentally induced severe drought on gas exchange of large seedlings of two Nothofagus species. Values on $x$-axis are in reverse order to illustrate that the volumetric water content (VWC) decreased during the experiment. Regressions and interspecific comparisons - when corresponded - were analyzed with standardized major axes (SMA). Respiration rates: $N$. dombeyi $(n=44)$, respiration does not relate to volumetric water content (VWC; $p=0.11$ ); $N$. nitida $(n=37)$, respiration does not relate to VWC $(p=0.29)$. Photosynthesis rate: $N$. dombeyi $(n=45), \log$ Photosynthesis $=-0.048+0.0308 \times \mathrm{VWC}$ $(p=0.0000) ; N$. nitida $(n=46), \log$ Photosynthesis $=-0.511+0.052 \times$ VWC $(p=0.0000)$. Stomatal conductance: $N$. dombeyi $(n=45), \log$ Conductance $=-2.13+0.00721 \times$ VWC $(p=0.0000) ; N$. nitida $(n=46)$, $\log$ Conductance $=-2.35+0.01103 \times \operatorname{VWC}(p=0.0000)$. For regression of respiration and VWC, species did not differ in slopes $(p=0.95)$ neither in elevations $(p=0.25)$. Slopes of regressions of photosynthesis and VWC differed between species $(p=0.002)$. For regression of stomatal conductance and VWC, species did not differ in their slopes $(p=0.08)$ neither in their elevations $(p=0.1)$

the proportion of tissues associated with the capture and transport of water (roots and sapwood; Chaves et al. 2009). Plants can also reduce carbon demands of attached tissues through leaf shedding, since carbohydrates may be exported from unproductive leaves (Newell et al. 2002). Thus, seedlings of $N$. dombeyi at drought ${ }_{95 \%}$ could have improved their carbon balance by shedding leaves to reduce wholeplant respiratory costs and by re-allocating carbohydrates from older to younger leaves.

Although the seedlings analyzed for NSC in this study were harvested at an extremely severe degree of drought, the concentration of carbon reserves in $N$. nitida-the species that experienced carbon depletion-was significantly high, when compared to control seedlings. Similar results have been found in seedlings of Pinus nigra (Girard et al. 1997), where starch concentration in roots, while reduced, remained high even in seedlings that died due to drought. The question of how long carbon reserves are available as a replacement of photosynthetic products is an issue that has been receiving increasing attention in the last years (e.g., Millard et al. 2007; Sala et al. 2010). It has been stated that essential plant functions, such as the production of root exudates that enhance nutrient-cycling and thus the supply of nitrogen, may impose a threshold on NSC mobilization (Millard et al. 2007). Consistently, leaf nitrogen concentrations were mostly unaffected by drought in both species. Drought has been found to impose impediments on carbon mobilization and translocation (Carpenter et al. 2008; Ruehr et al. 2009), increasing the level of carbon reserves that is unavailable. The fact that no positive association between photosynthesis and NSC concentration was found in seedlings of $N$. nitida at drought $_{95 \%}$ suggests that there has been indeed a failure to retrieve carbon reserves. In view of a growing number of studies invoking carbon starvation as the mechanism causing drought-induced tree mortality (Adams et al. 2009; Allen et al. 2010; Bréda et al. 2006; Liang et al. 2003; McDowell et al. 2009), it is important to note that some plants (e.g., seedlings in the current study) may die under drought conditions even when they contain important levels of carbon reserves.

In conclusion, a drought as severe as the one close to causing mortality promoted reductions in photosynthesis of the two Nothofagus species, though carbon storage was depleted only in one of them; the relatively more droughtsusceptible $N$. nitida. Rather, drought promoted an increase of NSC in the relatively more drought-resistant species $(N$. dombeyi) suggesting that in this species the constraints on the use of carbon were stronger than the constraints on the carbon gain. These results support the proposal of Sala et al. (2010), i.e., the relative sensitivity of carbon sources and sinks to water stress varies depending on the species. This is similar to what Regier et al. (2009) found: carbon depletion is more probable in genotypes less adapted to drought. Recent studies based on gas exchange measurements propose that curtailed photosynthesis and continued respiration can lead to carbon depletion and eventually to carbon starvation (Adams et al. 2009; McDowell et al. 2008). In this study, however, if carbon balance would have been simply inferred from gas exchange, one would have mistakenly concluded that both species had experienced carbon depletion. Therefore, it is concluded that direct quantifications of the variations in carbon storage through NSC analyses are essential to evaluate if carbon depletion 
has really happened, and this should be considered by future research focusing on the search of universal explanations of drought-induced tree mortality.

Acknowledgments This research was funded by the Fondo Nacional de Ciencia y Tecnología (Fondecyt) (1030663). Fondecyt (1040913) provided the time domain reflectometry equipment. I thank the anonymous reviewers for a very constructive criticism of my study; Brian Reid, Kyla Zaret, and Celine Boisvenue for the language support; Alex Fajardo, Anna Sala, and Günter Hoch for the comments and suggestions on earlier versions of this manuscript; Chris Lusk, Luis Corcuera, and Alejandra Zuñiga-Feest for the scientific and logistic support during the development of the experiment; and Ernesto Gianoli who kindly lent me an IRGA.

\section{References}

Adams HD, Guardiola-Claramonte M, Barron-Gafford GA, Villegas JC, Breshears DD, Zou CB, Troch PA, Huxman TE (2009) Temperature sensitivity of drought-induced tree mortality portends increased regional die-off under global-change-type drought. Proc Natl Acad Sci USA 106:7063-7066

Allen CD, Macalady AK, Chenchouni H, Bachelet D, McDowell N, Vennetier M, Kitzberger T, Rigling A, Breshears DD, Hogg EH et al (2010) A global overview of drought and heat-induced tree mortality reveals emerging climate change risks for forests. For Ecol Manag 259:660-684

Almeyda E, Saez F (1958) Recopilación de datos climáticos de Chile y Mapas Sinópticos respectivos. Ministerio de Agricultura, Santiago de Chile

Bréda N, Huc R, Granier A, Dreyer E (2006) Temperate forest trees and stands under severe drought: a review of ecophysiological responses, adaptation processes and long-term consequences. Ann For Sci 63:625-644

Bryla DR, Bouma TJ, Hartmond U, Eissenstat DM (2001) Influence of temperature and soil drying on respiration of individual roots in citrus: integrating greenhouse observations into a predictive model for the field. Plant Cell Environ 24:781-790

Carpenter L, Pezeshki S, Shields F (2008) Responses of nonstructural carbohydrates to shoot removal and soil moisture treatments in Salix nigra. Trees - Struct Funct 22:737-748

Chapin FS, Schulze ED, Mooney HA (1990) The ecology and economics of storage in plants. Ann Rev Ecolog Syst 21:423-447

Chaves MM, Flexas J, Pinheiro C (2009) Photosynthesis under drought and salt stress: regulation mechanisms from whole plant to cell. Ann Bot - London 103:551-560

Falster DS, Warton DI, Wright IJ (2003) Standardised major axis tests and routines. Version 1.0. http://www.bio.mq.edu.au/ecology/ SMATR. Department of Biological Sciences, Macquarie University, Sydney, NSW 2109, Australia

García-Plazaola JI, Becerril JM (2000) Effects of drought on photoprotective mechanisms in European beech (Fagus sylvatica L.) seedlings from different provenances. Trees - Struct Funct $14: 485-490$

Girard S, Clement A, Cochard H, Boulet-Gercourt B, Guehl J-M (1997) Effects of dessication on post-planting stress in bare-root Corsican pine seedlings. Tree Physiol 17:429-435

Guehl JM, Clement A, Kaushal P, Aussenac G (1993) Planting stress, water status and non-structural carbohydrate concentrations in Corsican pine seedlings. Tree Physiol 2:173-183

Hansen J, Moller I (1975) Percolation of starch and soluble carbohydrates from plant tissue for quantitative determination with anthrone. Anal Biochem 68:87-94
IPCC (2007) Climate Change 2007: the physical science basis. Contribution of Working Group I to the Fourth Assessment Report of the Intergovernmental Panel on Climate Change

Latt CR, Nair PKR, Kang BT (2001) Reserve carbohydrate levels in the boles and structural roots of five multipurpose tree species in a seasonally dry tropical climate. For Ecol Manag 146:145-158

Liang E, Shao X, Kong Z, Lin J (2003) The extreme drought in the 1920 s and its effect on tree growth deduced from tree ring analysis: a case study in North China. Ann For Sci 60:145-152

Liu HS, Li FM, Xu H (2004) Deficiency of water can enhance root respiration rate of drought-sensitive but not drought-tolerant spring wheat. Agric Water Manag 64:41-48

Ludovici KH, Allen HL, Albaugh TJ, Dougherty PM (2002) The influence of nutrient and water availability on carbohydrate storage in loblolly pine. For Ecol Manag 159:261-270

Lusk CH, Piper FI (2007) Seedling size influences relationships of shade tolerance with carbohydrate-storage patterns in a temperate rainforest. Funct Ecol 21:78-86

McDowell N, Pockman WT, Allen CD, Breshears DD, Cobb N, Kolb T, Plaut J, Sperry J, West A, Williams DG et al (2008) Mechanisms of plant survival and mortality during drought: why do some plants survive while others succumb to drought? New Phytol 178:719-739

McDowell NG, Allen CD, Marshall L (2009) Growth, carbon-isotope discrimination, and drought-associated mortality across a Pinus ponderosa elevational transect. Glob Chang Biol 16:399-415

Millard P, Sommerkorn M, Grelet G-A (2007) Environmental change and carbon limitation in trees: a biochemical, ecophysiological and ecosystem appraisal. New Phytol 175:11-28

Newell E, Mulkey S, Wright J (2002) Seasonal patterns of carbohydrate storage in four tropical tree species. Oecologia 131:333-342

Parker J, Patton RL (1975) Effects of drought and defoliation on some metabolites in roots of black oak seedlings. Can J For Res 5:457-463

Percival G, Sheriffs CN (2002) Identification of drought-tolerant woody perennials using chlorophyll fluorescence. J Arb 28:215223

Piper FI, Corcuera LJ, Alberdi M, Lusk CH (2007) Differential photosynthetic and survival responses to soil drought in two evergreen Nothofagus species. Ann For Sci 64:447-452

Piper F, Reyes-Díaz M, Corcuera L, Lusk C (2009) Carbohydrate storage, survival, and growth of two evergreen Nothofagus species in two contrasting light environments. Ecol Res 24:1233-1241

Regier N, Streb S, Cocozza C, Schaub M, Cherubini P, Zeeman SC, Frey B (2009) Drought tolerance of two black poplar (Populus nigra L.) clones: contribution of carbohydrates and oxidative stress defence. Plant Cell Environ 32:1724-1736

Roe JH (1934) A photometric method for the determination of fructose in blood and urine. J Biol Chem 107:15-22

Ruehr NK, Offermann CA, Gessler A, Winkler JB, Ferrio JP, Buchmann N, Barnard RL (2009) Drought effects on allocation of recent carbon: from beech leaves to soil $\mathrm{CO}_{2}$ efflux. New Phytol 184:950-961

Sala A, Hoch G (2009) Height-related growth declines in ponderosa pine are not due to carbon limitation. Plant Cell Environ 32:22-30

Sala A, Piper F, Hoch G (2010) Physiological mechanisms of droughtinduced tree mortality are far from being resolved. New Phytol 186:274-281

Sutton BG, Ting IP, Sutton R (1981) Carbohydrate metabolism of cactus in a desert environment. Plant Physiol 68:784-787

Tissue DT, Wright SJ (1995) Effect of seasonal water availability on phenology and the annual shoot carbohydrate cycle of tropical forest shrubs. Funct Ecol 9:518-527 
van Mantgem PJ, Stephenson NL, Byrne JC, Daniels LD, Franklin JF, Fule PZ, Harmon ME, Larson AJ, Smith JM, Taylor AH et al (2009) Widespread increase of tree mortality rates in the Western United States. Science 323:521-524

Veblen TT, Donoso C, Kitzberger T, Rebertus AJ (1996) Ecology of Southern Chilean and Argentinian Nothofagus forests. In: Veblen TT, Hill RS, Read J (eds) The ecology and biogeography of
Nothofagus forests. Yale University Press, New Haven, pp 293 353

Weinberger P (1973) The regeneration of the Araucano-patagonic Nothofagus species in relation to microclimatic conditions. Tuatara 22:233-244

Würth MKR, Peláez-Riedl S, Wright SJ, Körner C (2005) Non-structural carbohydrate pools in a tropical forest. Oecologia 143:11-24 